\title{
FORMAÇÃO DE PROFESSORES PARA A JUSTIÇA SOCIAL: UMA REFLEXÃO SOBRE A DOCÊNCIA NA RESIDÊNCIA PEDAGÓGICA ${ }^{1}$
}

\author{
FORMÁCION DE PROFESORES PARA LA JUSTICIA SOCIAL: UNA \\ REFLEXIÓN SOBRE LA DOCENCIA EN LA RESIDENCIA PEDAGOGICA
}

\author{
TEACHER EDUCATION FOR SOCIAL JUSTICE: A \\ REFLECTION ON TEACHING IN PEDAGOGICAL RESIDENCE
}

Helena Amaral da FONTOURA ${ }^{2}$

\begin{abstract}
RESUMO: O presente trabalho aborda um processo de formação de professores na forma de Residência Pedagógica, desenvolvido em uma instituição pública do Rio de Janeiro, projeto que atende prioritariamente a egressos da instituição, mas que vem recebendo interessados em discutir suas práticas docentes e aprimorar o que fazem. $\mathrm{O}$ recorte escolhido para esse artigo enfatiza a formação de professores para a justiça social, a partir de Zeichner, que defende um programa de formação radical em que ensinar é visto como uma atividade crítica e o docente como um profissional que investiga e reflete sobre sua prática. Entendemos que a reflexão sobre o fazer docente é uma condição política fundamental da formação do professor, sendo que a sua formação reflexiva deve vincular-se à luta pela construção da justiça social e intelectual no país. Cabe à sociedade, como um todo, e aos responsáveis pela elaboração de políticas públicas, em todos os níveis, buscarem assegurar que a escola cumpra seu papel de espaço privilegiado na promoção dos direitos humanos, procurando garantir a inclusão, o respeito e a valorização das diferenças, tentando garantir que o espaço escolar propicie liberdade de expressão, promoção dos direitos humanos, inclusão educacional, em outras palavras, justiça social.
\end{abstract}

PALAVRAS-CHAVE: Formação de professores. Justiça social. Residência pedagógica.

RESUMEN: Este artículo analiza el proceso de formación de profesores en la forma de residencia pedagógica en una institución pública en Río de Janeiro, que sirve principalmente a los egresados de la institución, pero que está consiguiendo interesó otros a examinar sus prácticas de enseñanza y mejorar lo que hacen. El corte elegido para este artículo hace hincapié en la formación de maestros por la justicia social, de Zeichner, que aboga por un programa de formación radical en que la enseñanza es vista como una actividad crítica y al docente como un profesional que investiga y reflexiona sobre su práctica. Entendemos que la reflexión sobre la enseñanza es política fundamental de la formación del profesor, y su formación debe enlazarse a la reflexiva lucha por la justicia social y la construcción intelectual en el país. Depende de

${ }^{1}$ FAPERJ - Fundação Carlos Chagas de Amparo à Pesquisa do Estado do Rio de Janeiro.

${ }^{2}$ Professora Associada Departamento de Educação Faculdade de Formação de Professores Universidade do Estado do Rio de Janeiro. Docente do Programa de Pós-Graduação em Educação - processos formativos e desigualdades sociais. Email: helenafontoura@gmail.com

RIAEE - Revista Ibero-Americana de Estudos em Educação, v.12, n.1, p. 120-133 , 2017. 
la sociedad en su conjunto y los responsables de elaborar las políticas públicas, en todos los niveles, procurar que la escuela cumple su papel como un espacio privilegiado en la promoción de los derechos humanos, que buscan garantizar la inclusión, el respeto y la apreciación de las diferencias, tratando de asegurar que el espacio de la escuela fomenta la libertad de expresión, derechos humanos, inclusión educativa, en otras palabras, la justicia social.

PALAVRAS CLAVE: Formación docente. Justicia social. Residencia pedagógica.

ABSTRACT: This paper discusses the process of teacher training in the form of Pedagogical Residence developed at a public institution in Rio de Janeiro, serving primarily for graduates of the institution, but opened to others who are interested in discussing their teaching practices and improve what they do. The cutoff chosen for this article emphasizes the training of teachers for social justice, concept by Zeichner, who advocates a radical training program in which teaching is seen as a critical activity and the teacher as a professional who investigates and reflects on his/hers practice. We understand that the reflection on teaching is making fundamental policy of teacher formation, and their training should be bound to the reflective struggle for social justice and intellectual construction in the country. It is up to society as a whole, and those responsible for drawing up public policies, at all levels, to seek to ensure that the schoolfulfills its role as a privileged space in promoting human rights, seeking to ensure the inclusion, respect and appreciation of differences, trying to ensure that school can be a space that fostersfreedom of expression, human rights, educational inclusion, in other words, social justice.

KEYWORDS: Teacher education. Social justice. Pedagogical residence.

\section{Introdução}

Educar envolve ensinar e aprender a cultura que nos cerca, com todas as suas especificidades, direitos e deveres do exercício cidadão. Segundo o Art. 205 da Constituição Federal, a educação é direito de todos, dever do Estado e da família, devendo ser promovida e incentivada com a colaboração de todas as instâncias da sociedade; entre suas finalidades constam o desenvolvimento integral da pessoa, a preparação para o exercício pleno da cidadania, a promoção da igualdade e a qualificação para o trabalho. Ao referir-se à cidadania e à dignidade da pessoa humana, entre seus princípios fundamentais, nossa Carta Magna assegura que a educação deve ser apropriadamente inserida em um contexto maior, buscando eliminar desigualdades sociais, tornando-se uma questão de justiça social. A questão que aponta para um dos debates fundamentais do campo da educação - a sua relação com a 
sociedade em que está inserida - permeia grande parte das discussões quando se pensa nas contradições do sistema instituído e seus reflexos nos processos educativos.

\section{Sobre justiça social}

Os princípios de justiça social se estruturam em torno de igualdade de oportunidades para todos, resguardando liberdade e demais direitos, com vistas à aquisição e manutenção do equilíbrio social. Liberdades individuais são fundamentais para a vida em sociedade, ao mesmo tempo em que a justiça na distribuição de bens culturais também o é, ou seja, o bem-estar social é função do bem-estar coletivo em uma sociedade que busca equilíbrio e justiça social. Assim, situações de desigualdade educacional, por exemplo, ou de renda, mais comumente, geram inúmeros problemas sociais, pois prejudicam o funcionamento equitativo da sociedade, haja vista as várias situações de convulsão social no mundo todo.

A concepção de equidade implica na igualdade de todos os cidadãos em termos de possuírem as mesmas oportunidades para obterem resultados semelhantes, tendo em vista as diferentes condições de existências desses cidadãos. Zeichner (2008), analisando qualitativamente diferentes programas de Formação de Professores para a Justiça Social (FPJS), se propõe a "esboçar os argumentos feitos pelos defensores dessa agenda, a variedade de práticas de formação de professores que têm sido estabelecidas dentro da ampla abrangência da justiça social" (p. 15-16). Além disso, propõe-se a apresentar sua crítica construtiva não como um observador externo, mas como "alguém que está envolvido nesse próprio trabalho todos os dias" (p. 15-16), premissa da qual compartilhamos.

$\mathrm{O}$ autor enfatiza a necessidade de aprofundar o que se pretende com esse rótulo e de saber como as várias interpretações de FPJS influenciam professores e seus alunos. Isso vai além de uma "celebração da diversidade", procurando formar professores que são determinados e "capazes de trabalhar dentro e fora de suas salas de aula, a fim de mudar as desigualdades que existem tanto no ensino, quanto na sociedade como um todo" (p. 17). Aponta ainda o autor que existe um reconhecimento das dimensões sociais e políticas do ensino, juntamente com suas outras dimensões, e um reconhecimento das contribuições dos professores para aumentar as oportunidades de vida de seus alunos. Em sua pesquisa aponta para o fato de que há variações entre as 
propostas de diferentes programas estudados que se propõem a desenvolver justiça social. Para ele, uma dimensão, ao longo da qual os programas de FPJS variam, é o grau em que enfatizam "interagir com culturas e esforços para construir justiça social, em oposição a estudar sobre culturas e trabalho de justiça social” (p. 21)

Temos também a contribuição de McDonald (2008), autora que pesquisa o mesmo tema, pergunta como os programas de formação de professores preparam para a realidade de salas de aula cada vez mais diversa. Procura, através de um estudo de caso qualitativo, comparar dois programas de formação de professores com a preocupação de implementar a justiça social, avaliando especialmente as oportunidades de aprendizagem dos participantes sobre o tema nos processos de preparação de futuros docentes. Traz uma extensa revisão de literatura sobre seu tema de pesquisa além de descrever a implementação da justiça social na prática, através de uma survey, com foco nas crenças, valores e atitudes dos participantes sobre ensinar e o que é necessário para uma boa preparação, em uma triangulação de métodos que permitiu analisar conceitos de forma ampla, utilizando dados qualitativos e dados quantitativos. Conclui que parece ser mais viável, nos programas estudados, ensinar conceitos sobre justiça social do que produzir práticas; destaca a autora a importância de estágios supervisionados como possibilitadores de ampliação de oportunidades para futuros docentes aprenderem sobre justiça social, especialmente se for em ambientes em que a diversidade seja um fato. Interessante notar que a pesquisadora propõe que formadores de professores também possam pensar em suas práticas relacionadas à justiça social, vendo como atividades acadêmicas propostas que ampliam as possibilidades formativas em um mundo de desigualdades sociais tão presentes e intensas.

Em nosso papel de formadores necessitamos ter claro que uma investigação sobre meios de levar questões relacionadas às desigualdades sociais para a mesa das discussões entre e com professores de todos os níveis é mais do que uma necessidade premente. Se não adotarmos posições firmes nessa direção, podemos estar perdendo uma oportunidade preciosa de reverter um quadro bastante sério de deterioração social. Educadores podem, em seus espaços de trabalho, buscar garantir participação de segmentos da população historicamente segregados e alijados dos processos históricos de transformação social. Podemos formar sujeitos atuantes nos processos transformativos, com vistas a superar as distorções, beneficiando a todos os membros da sociedade. 
Silva e Tavares (2010), discutindo políticas e fundamentos da educação em direitos humanos, trazem que o trabalho da escola, em uma proposta democratizante, deve priorizar as capacidades comunicativas dos alunos, de modo a honrar o compromisso de capacitar professores e alunos para serem autores e atores do projeto de sociedade em que vivem. As autoras esclarecem que o Plano Nacional de Educação em Direitos Humanos - PNEDH (BRASIL, 2007) aponta que devemos reconhecer, em um processo formativo, a pluralidade e a alteridade como condições básicas para o exercício da escrita, da criatividade e da crítica, de modo a haver debate de ideias e promoção da diversidade como condições inerentes ao processo educativo. O PNEDH configura um resultado do movimento nacional e internacional em defesa dos direitos humanos, do fortalecimento da democracia. Nesse sentido, tem como perspectiva fortalecer o regime democrático, com o objetivo de oferecer condições para a concretização dos direitos humanos, considerando a indivisibilidade e a interdependência entre todos os direitos.

Assim, uma escola que promova educação para os direitos humanos e para a justiça social deve procurar garantir igualdade de oportunidades e espaços de participação a todos os membros da comunidade escolar, de modo a possibilitar que todos incorporem práticas de cidadania vivenciadas no cotidiano. Completam as autoras sinalizando para a necessidade de mobilizar os que pensam e fazem educação no país, especialmente na educação básica, considerada como um dos pilares de sustentação fundamental para dar condições e continuidade nos processos educativos, com vistas a sistematizar processos de reflexão e estruturação da área de direitos humanos e justiça social.

\section{Residência Pedagógica: processo de formação docente}

Gatti, Barreto e André (2011), em pesquisa sobre políticas docentes no Brasil, enfatizam a necessidade de serem realizadas ações de formação em serviço que reforcem aprendizados anteriores e deem continuidade a esses, com vistas ao aprimoramento profissional constante do professor. Como já afirmamos, este processo continua a se construir nos anos iniciais da prática docente, e é justamente em função do reconhecimento desses fatores que desenvolvemos nossa proposta de Residência 
Pedagógica (FONTOURA, 2011a), uma vez que defendemos que docentes em formação e recém formados pela Universidade podem ainda contar com o apoio dos formadores, o que se torna mais difícil quando se veem sozinhos nas escolas e, no caso de não se encontrarem inseridos em programas como o supra mencionado, podem vir a ser levados a desistirem da profissão por falta de terem com quem dialogar sobre suas angústias e dificuldades, inerentes a todos os profissionais iniciantes na docência.

Em nosso projeto de formação docente, que chamamos Residência Pedagógica, reunimos professoras e professores em atuação nas escolas das diversas redes de ensino, em sua maioria, egressas e egressos dos cursos de licenciatura de uma instituição pública do Estado do Rio de Janeiro, com vistas a discutir práticas e situações vividas, bem como dilemas da prática docente (GIMENO SÁCRISTAN, 1992), estabelecendo redes de comunicação e proteção. Tal trabalho pretende assegurar que o início da docência ocorra com o suporte de pares e que favoreça a permanência dos novos docentes na profissão, fortalecidos por reflexões coletivas e individuais, com o apoio do grupo. Esta atividade já acontece desde 2009, sendo aberta a quem nos procura e produzindo pesquisas, publicações e escritos diversos, além de estimular participantes a frequentarem eventos, falarem de suas experiências, apresentarem seus progressos e refletirem sobre as dificuldades encontradas, assim como pensar em conjunto formas de superá-las.

Tornar-se professor é um longo processo. Os que chegam à Universidade para institucionalizar sua formação em nível superior não são tábulas rasas, são estudantes que observaram e viveram muitas práticas de professores ao longo de suas vidas de estudantes, que formam a visão que têm da docência, do que querem ou não para suas vidas profissionais. As crenças às vezes muito arraigadas, de tão forte que são os modelos, que a mudança fica dificultada, até mesmo o questionamento das crenças não é tarefa fácil para formadores. Por apostarmos na relação universidade-escola básica, desenvolvemos um trabalho que acolhe docentes em formação como sujeitos de seus saberes e fazeres, plenos de vivências anteriores ao ingresso na formação formal, e que podem refletir sobre experiências e crenças com vistas a fortalecer sua docência, permanecendo nela por convicção e prazer.

Assim, nossa premissa é a de que uma formação de professores para o saber e para a vida é um processo, nunca concluído, sempre em vir a ser, mas com etapas conquistadas, ao longo do percurso. O professor se desenvolve continuamente, como pessoa e como profissional, adquirindo conhecimentos e experiências, produzindo 
saberes e construindo sua identidade. Nós, formadores de professores, temos que ter preocupações com a qualidade do ensino que oferecemos aos nossos licenciandos e aos que se formam em nossas instituições, ingressando no mercado de trabalho. Tal processo formador deverá ter implicação direta na qualidade do ensino oferecido à população que procura as escolas públicas, em especial, mas não excluindo outros espaços para os quais formamos nossos professores.

Temos, em Nóvoa (1992), contribuições que apontam que os problemas dos docentes não são apenas instrumentais. $\mathrm{Na}$ verdade, todos comportam situações que envolvem outros aspectos, trazendo incertezas, conflitos de valores, mas principalmente, constituindo-se como únicos, portanto exigindo profissionais competentes e que demonstrem capacidade reflexiva. Comenta o referido autor, quando visamos à qualidade do ensino, é fundamental que abordemos qualquer proposta de formação a partir de três eixos estratégicos: a pessoa do professor e sua experiência, a profissão e seus saberes e a escola e seus projetos. Para ele, a prática do professor, embora momentaneamente individual, estará sempre carregada das condições políticosociais e institucionais nas quais está inserida (NÓVOA, 2003). A Universidade tem, assim, um papel importante ao propor estratégias formativas que desenvolvam professores em formação, na ótica medidora.

Para Placco e Souza (2012), a mediação entre formador e formando tem um papel muito importante de mobilizar diversos aspectos, como autonomia, parcerias entre docentes, aprimoramento de relações interpessoais e intergrupais, desenvolvimento de hábitos de estudo por parte dos docentes envolvidos, o que pode vir a facilitar intervenções na formação de discentes sob sua responsabilidade, aprimorando assim as relações entre professores e alunos, tão fundantes em um processo de ensino e aprendizagem bom para todos. Um importante e significativo aspecto desse processo é a construção de espaços de desenvolvimento de professores, estabelecido na relação universidade-escola e na motivação para que professores pesquisem, olhem suas práticas de outras formas, se percebam em um contexto e não como peças soltas e guiadas por outros, tendo como decorrência melhorias do trabalho desenvolvido nas escolas parceiras.

Aranha (2011), por sua vez, argumenta que o avanço na educação básica necessita, além de uma boa formação docente, de uma melhoria nas condições em que o trabalho é realizado, assim como de uma alteração cultural sobre o ser docente, com o resgate da dignidade profissional. Esta, segundo o referido autor, certamente deverá ser 
atravessada pela intensa discussão sobre a questão da diversidade, englobando todos os sujeitos envolvidos, tanto docentes, discentes, famílias e profissionais da escola, assim como a comunidade de entorno. Tais considerações remetem aos elos da cadeia de imbricamentos entre dimensões micro e macro, em termos da inserção desse universo nas políticas públicas que nos regulam e que, muitas vezes, passam ao largo de nossa ciência. Ainda para Aranha (2011), o respeito à diversidade relaciona-se, intimamente, ao direito à inclusão social. $\mathrm{O}$ autor, sem pretender aprofundar nas múltiplas compreensões do que seja a inclusão propriamente dita, registra que o respeito ao 'diferente' não é totalmente coerente se não vier acompanhado da compreensão desse 'diferente' ter os mesmos direitos de todos, entre os quais destaca a educação, em todos os seus níveis. Assim, a garantia do direito à diversidade, na política educacional, bem como sua efetivação, por meio da justiça social, da inclusão e dos direitos humanos, implica na superação de toda e qualquer prática de violência, discriminação, proselitismo e intolerância de qualquer ordem.

Em função do exposto, é interessante notar que, frequentemente, em nossos encontros na Residência Pedagógica, temos percebido que as concepções sobre diversidade trazidas em debates apresentam aspectos individuais, isto é, as ideias apresentadas pelos professores sobre alunos pertencentes a níveis socioeconômicos e culturais plurais e/ou portadores de experiências de vida diferentes das suas próprias, por exemplo, focalizam aspectos centrados em características como a personalidade e motivação do aluno, ou em relatos de histórias familiares de descuido, vícios ou violências diversas, desconsiderando fatores mais contextuais. Através da reflexão fomentada em nosso trabalho, buscamos trazer tais contextos para os debates, uma vez que consideramos tal perspectiva crucial para ampliar e significar algumas das posturas adotadas em decorrência tanto do desconhecimento como da não consideração das questões macroestruturais, ao abordarem situações do cotidiano escolar.

Para tal atitude, entendemos que a noção de diversidade inclui o respeito ao diferente, reconhecendo-o, na sua diferença, assim como seus direitos de cidadania, que devem ser os mesmos de todos. Candau (2008) chama a atenção para o fato de que as relações culturais não são nem idílicas nem românticas, mas sim construídas na história, atravessadas pelas questões de poder, por hierarquias, preconceitos e discriminações de toda ordem. Aponta a autora para a necessidade do rompimento com o chamado 'daltonismo cultural' e o reconhecimento do 'arco-íris das culturas' como uma nova prática educativa a ser implementada no dia a dia das escolas. Nesse sentido, a 
negociação cultural e a percepção da escola como espaço de crítica e produção cultural constituem-se iniciativas fundamentais para o arejamento e para o avanço das práticas pedagógicas.

O espaço da Residência Pedagógica desempenha as funções principais de um espaço universitário, a saber: em sua vertente de pesquisa, busca analisar como professores iniciantes estabelecem as relações com o conhecimento e com o "ser professor", a partir de suas experiências e histórias de aprendizagem, assim como analisar práticas desenvolvidas, discutindo formas de enfrentamento dos dilemas nos diferentes espaços da pesquisa, a partir das vozes dos envolvidos. Em sua vertente de extensão universitária, busca construir um espaço para egressos que estão na prática docente, com vistas a encaminhar possibilidades de ressignificação dos seus dilemas, fortalecer práticas institucionais de formação docente, por meio dos encontros e das relações interinstitucionais, fomentando as possibilidades de permanência na atividade docente. A vertente ensino, por sua vez, transversaliza todo o processo e, ao mesmo tempo, estrutura as práticas, tanto como tema de interesse quanto como processo em desenvolvimento, promovendo sua análise no contexto das próprias atividades plurais propostas no grupo.

Os encontros já realizados, no contexto desse programa, trouxeram amplas possibilidades de discussão sobre as concepções trazidas pelos participantes, tais como: trabalho docente, relações de ensino-aprendizagem, relação professor-aluno, concepções de currículo, noção do que seja conhecimento, assim como sobre a importância de se planejar a ação docente e de se pensar sobre seus desdobramentos. Os referenciais trazidos pela academia foram importantes na construção do processo, assim como os referenciais que os professores trouxeram do chão da escola. Esse movimento originou a escrita de um livro, no qual os participantes foram se organizando para compartilhar suas experiências em artigos, em sua grande maioria, orientados pelos docentes da universidade, garantindo a autoria dos agora "escritores de suas práticas" (FONTOURA, 2011a).

Em Fontoura (2011b) apresentamos alguns desdobramentos do trabalho que vem sendo feito desde 2009 na instituição, relatando que, desde o início, recebemos os egressos em reuniões mensais aos sábados, visando, principalmente, promover encontros e ouvir as falas sobre sua inserção na docência, discutindo dilemas e trocando experiências. Como o grupo sempre foi aberto, recebemos, também, bolsistas de Iniciação Científica de professoras responsáveis pelo Projeto Egressos, assim como 
docentes das redes atuando em escolas parceiras (como campo de estágio ou colaboradoras em outros projetos). Contamos, ainda, com mestrandos em Educação, sejam egressos ou não da instituição.

Alguns eixos básicos nortearam as ações, dentre os quais: problematizar a prática pedagógica, buscar compreender a realidade educacional na qual os participantes estavam inseridos, discutir situações vividas e a forma de superar os dilemas (GIMENO SACRISTÁN, 1992). É interessante observar que, em todos os encontros, temos desenvolvido algum trabalho com a dimensão individual do ser professor, através de um relato oral, de uma representação gráfica, de uma escrita de si ou, mesmo, a partir de depoimentos mais completos relacionados ao tema do encontro, que se tornam coletivos nas trocas entre os envolvidos.

Dialogamos, lemos textos, rimos de nossas semelhanças e dificuldades, todos nos vendo como participantes, procurando não enfatizar a crença da pretensa superioridade da universidade em face da escola básica. Essa postura foi sendo construída por nós no contexto do grupo, apoiados em Elliott (1998), que aponta que, se não houver mudança de base epistemológica, pode se deflagrar uma tensão entre professores da escola básica e professores universitários. Em sua formulação, o autor compartilha conosco a noção de que a colaboração entre professores da universidade e professores da escola básica é um marco do que chama de investigação-ação. Em tal proposta, a teoria e a prática não se separam, mas sim, interagem, tendo como eixo questões relacionadas aos processos de aprendizagem, bem como ao campo de atuação de universidades e de escolas.

Em nossa atuação na Residência Pedagógica, encontramos alguns temas que consideramos importantes, nesse sentido, para quem forma professores para atuarem em uma sociedade desigual, que necessita ser repensada e revista, de modo a garantirmos um futuro próximo mais harmônico para os que nela vivem. Trata-se, pois, de preparar professores que possam dar uma educação de qualidade para as classes populares, para superar um sistema desigual de escolarização, buscando outros tipos de soluções fora do sistema atual, a fim de formar profissionais para todas as escolas. Desta forma, trata-se de desenvolver, na formação docente, um processo de afiliação com a escola e com a comunidade, criando uma cultura de pesquisa nas escolas, pelo exame crítico e diuturno das próprias práticas. 


\section{Considerações Finais}

A partir da experiência desenvolvida, colocamos uma questão, ouvindo nossos impasses e desafios: o que é possível fazer no cotidiano das escolas e das agências formadoras de professores para tratar da questão da justiça social?

Em nível macro, sabemos da necessidade de implementar políticas educacionais voltadas para uma real valorização da escola e do magistério, que vão desde a melhoria dos salários dos profissionais de ensino e das condições físicas e materiais das escolas, até medidas mais específicas, tais como maior investimento e incentivo à instituição de espaços coletivos de discussão, dentro dos horários escolares, que tenham, por objetivo, proporcionar, aos educadores, momentos de reflexão sobre os problemas que afetam o cotidiano escolar.

No nível mais específico de atuação, que se refere ao trabalho que pode ser realizado no interior da escola, a experiência aqui descrita parece ter apontado para vários caminhos que podem ser pensados para enfrentar os desafios de superar as desigualdades no espaço escolar, tais como: o resgate do aluno, como sujeito do processo educativo; o cuidado com o espaço físico e com as condições materiais da escola; as práticas participativas e de diálogo nas diferentes instâncias escolares, da sala de aula aos conselhos de escola; a promoção de espaços sistemáticos de reflexão coletiva dos professores sobre a prática educativa e seus problemas concretos; a intensificação das relações entre as famílias e a escola; o bom relacionamento interpessoal entre professores e alunos; a realização de atividades extraclasse, tais como esporte, teatro, excursões e grupos de música; o estímulo à participação dos alunos e alunas em diferentes órgãos e atividades da escola; e a integração da escola à dinâmica comunitária.

Enfatizamos a importância do diálogo como uma estratégia para se enfrentar as situações de desigualdade social, através do trabalho pedagógico, na construção de seres sociais com a capacidade de falar, de escutar, de dialogar e de trabalhar em cooperação. Para Freire (1970), a ação dialógica só pode se dar entre sujeitos, mesmo que de diferentes níveis de responsabilidade, mas sempre em comunicação. Assim, para o autor, "o diálogo, que é sempre comunicação, funda a colaboração" (FREIRE, 1970, p.166). Estabelecer o diálogo, no sentido dado por Freire, pode ser visto como um instrumento privilegiado na superação de situações que marcam desigualdades e preconceitos, em manifestações verbais ou não verbais. Nossa prática, nos encontros da 
Residência Pedagógica, tem sido no sentido de enfatizar esse diálogo, assim como a escuta e a busca de caminhos de forma coletiva e cooperativa.

Encontramos, nas situações discutidas no grupo, experiências que apontam para o fato de que o desenvolvimento de formas participativas de construção de normas é um dos fatores que podem contribuir significativamente para a construção de seres sociais capazes de falarem, de ouvirem, de respeitarem e de lutarem pela transformação da sociedade. Ao invés de punir alunos que 'não se comportam adequadamente no espaço escolar', por exemplo, trata-se de se estabelecerem regras, de forma coletiva, e que sejam passíveis de serem cumpridas, o que tem sido um caminho apontado para que se contornem os impasses disciplinares enfrentados por docentes.

A linguagem dialógica, assim concebida, constitui um importante instrumento de sobrevivência e de luta para a transformação da sociedade. Freire (1986), referindo-se a alunos das classes menos favorecidas, aponta que "não dominar as formas elitistas (de comunicação) só faria com que fosse mais difícil para eles sobreviverem na luta" (p. 91). Podemos refletir, aqui, sobre o fato de nos acharmos responsáveis pela transmissão de um mundo 'velho' aos nossos 'jovens' alunos. Devemos superar tal visão de modo a não termos um descompasso entre o que somos e o que achamos que somos enquanto figuras de autoridade, tanto de poder como de saber, ocasionando práticas autoritárias pelo simples fato de que não sabemos 'ser de outro jeito', por não termos tido, em nossa formação, elementos para pensar, por exemplo, um mundo em transição constante, em veloz evolução, e nos mantermos com nossa preocupação de 'passar' conteúdos estabelecidos.

No espaço da Residência Pedagógica, temos encontrado algumas evidências de um trabalho de inclusão bem sucedido, com o reconhecimento e valorização da diversidade como elemento enriquecedor do processo de ensino e aprendizagem. Tal visão tem se refletido em professores conscientes do modo como atuam, de modo a promoverem a aprendizagem de todos os alunos. Também tem resultado na cooperação, entre os implicados no processo educativo, dentro e fora da escola, assim como na valorização do processo sobre o 'produto' da aprendizagem. Temos, também, como resultados, a apresentação, por parte dos participantes, de enfoques curriculares, metodológicos e estratégias pedagógicas que apresentam maiores possibilidades de fomento à construção coletiva do conhecimento para todos, alunos e professores, independentemente de condições tidas como inicialmente desfavoráveis a tal processo. 
Não pretendemos "inventar a roda", propondo caminho único tanto para a resolução das dificuldades encontradas por professores iniciantes em seu ingresso no magistério ou, para garantir a sua permanência em uma docência comprometida com o bem comum e satisfatória como profissão, no sentido de uma atuação voltada para a diminuição das gritantes diferenças sociais em nosso país. Mas apostamos em um processo reflexivo e atuante de diálogo entre pares, argumentando que o mesmo pode reforçar as possibilidades de sucesso de nós, docentes, e de nossos alunos e alunas, considerando o espaço da Residência Pedagógica como uma das possibilidades bem sucedidas para formarmos professores para a justiça social.

\section{Referências}

ARANHA, AVS. Diversidade e formação docente: um desafio para o avanço da Educação. Form. Doc., Belo Horizonte,v. 03, n. 04, p. 54-61, jan./jul. 2011. Disponível em: <http://formacaodocente.autenticaeditora.com.br>. Acesso em: 15 janeiro de 2015.

BRASIL. Comitê Nacional de Educação em Direitos Humanos. Plano Nacional de Educação em Direitos Humanos. Brasília, DF: Secretária Especial dos Direitos Humanos, Ministério da Educação da Justiça, UNESCO, 2007. Disponível em: <http://portal.mj.gov.br/sedh/edh/pnedhpor.pdf>. Acesso em: 15 maio 2014.

CANDAU, Vera Maria. Multiculturalismo e educação: desafios para a prática pedagógica. In: CANDAU, Vera Maria; MOREIRA, Antônio. F. (Orgs). Multiculturalismo: diferenças culturais e práticas pedagógicas. Petrópolis: Vozes, 2008.

CANDAU, VMF. Educação em direitos humanos e diferenças culturais: questões e buscas. Revista Múltiplas Leituras, v.2, n. 1, p. 65-82, jan. / jun. 2009. Disponível em: $<$ https://www.metodista.br/revistas/revistas-

ims/index.php/ML/article/viewFile/328/326>. Acesso em: 15 agosto de 2015.

FONTOURA, HA. (Org.). Residência pedagógica: percursos de formação e experiências docentes na Faculdade de Formação de Professores da UERJ. Rio de Janeiro: Intertexto, 2011a.

FONTOURA, HA. Residência pedagógica: investigação-ação com professores egressos da Faculdade de Formação de Professores da UERJ. Revista de Educação Pública (UFMT), Cuiabá, MT, v.20, p.307-322, 2011 b.

FREIRE, P. Medo e Ousadia: o cotidiano do professor. Rio de Janeiro: Paz e Terra, 1986.

FREIRE, P. Pedagogia do Oprimido. Rio de Janeiro: Paz e Terra, 1970. 
GIMENO SACRISTÁN, J. S. Consciência e ação sobre a prática como libertação profissional dos professores. In NÓVOA, A. (Org.). Profissão professor. Porto: Porto Editora, 1992.

McDONALD, M. Desafios para a implementação da justiça social na formação de professores. In DINIZ-PEREIRA, J.E.; ZEICHNER, K,M. (Orgs.) Justiça Social: desafio para a formação de professores. Belo Horizonte: Autêntica, p.105-140, 2008.

NÓVOA, A. Diz-me como ensinas, dir-te-ei quem és e vice - versa. In: FAZENDA, I. (Org.). A pesquisa em educação e as transformações do conhecimento. São Paulo: Papirus, 2003.

NÓVOA, A. (Org.) Vidas de Professores. Lisboa: Porto Editora, 1992.

PLACCO, Vera Maria Nigro de Souza, SOUZA, Vera Lucia Trevisan. Saberes e Trabalho do professor: Que aprendizagens? Que formação?. In ENS, R.T. VOSGERAU, D.S.R.; BEHRENS, M. A. Trabalho do professor e saberes docentes. 2.ed. Curitiba, Champagnat, p. 83-100, 2012.

SILVA, Aida Maria Monteiro, TAVARES, Celma (Org.). Políticas e fundamentos da educação em direitos humanos. São Paulo: Cortez, 2010.

ZEICHNER, Kenneth M. Formação de professores para a justiça social em tempos de incerteza e desigualdades crescentes. In DINIZ-PEREIRA, J. E.; ZEICHNER, K. M. (Orgs.) Justiça Social: desafio para a formação de professores. Belo Horizonte: Autêntica, p.11-34, 2008.

\section{Como referenciar este artigo}

FONTOURA, Helena Amaral da. Formação de Professores para a Justiça Social: uma reflexão sobre a docência na Residência Pedagógica. Revista Ibero-Americana de Estudos em Educação, Araraquara, v.12, n.1, p. 120-133, 2017. Disponível em: <http://dx.doi.org/10.21723/riaee.v12.n1.7932>. E-ISSN: 1982-5587.

Submetido em: ago/2015

Aprovação final em: dez/2016 